\title{
"Fazendo a escolh a certa": tecnologias reprodutivas, práticas lésbicas e uso de bancos de sêmen
}

| ${ }^{1}$ Rosana Machin, ${ }^{2}$ Marcia Thereza Couto |

Resumo: A obtenção de sêmen para reprodução é uma questão central no projeto de filiação entre lésbicas e envolve consideraçôes em torno de ideais culturais, parentesco e princípios normativos/ legais. O estudo de natureza qualitativa foi realizado com lésbicas buscando a maternidade por meio de tecnologias reprodutivas e aquisição de sêmen em bancos no Brasil e no exterior. Foram realizadas entrevistas semiestruturadas com profissionais de saúde atuantes no campo de tecnologias reprodutivas (10) e lésbicas (10 casais) em São Paulo/SP entre 2010/2012. Há um desejo por maximizar conexōes estabelecendo um link da filiação com as características fenotípicas presentes na família e no casal, num arranjo que proporcione uma percepção de "natural" conexão, com a biologia como um importante símbolo do compartilhamento do vínculo criado. Em razão de uma alegada pouca disponibilidade de sêmen compatível com as demandas formuladas pelos casais, tem havido importação de sêmen para os procedimentos, acarretando uma série de novas questôes.

> Palavras-chave: Tecnologia reprodutiva; maternidade lésbica; bancos de sêmen.
1 Departamento de Política, Planejamento e Administração em Saúde, Instituto de Medicina Social da UERJ (IMS-UERJ). Rio de Janeiro-RJ, Brasil. Endereço eletrônico: gkornis@gmail.com

${ }^{2}$ Faculdade de Farmácia e Bioquímica, Universidade Federal de Juiz de Fora. Juiz de Fora-MG, Brasil. Endereço eletrônico: maria.helena@ufjf. edu.br 
As tecnologias reprodutivas (TR $)^{1}$ surgiram nos anos 1980 com o objetivo de contornar a infertilidade ao possibilitarem a gestação a casais heterossexuais inférteis, mas também abriram novas possibilidades para aqueles que vivem outras formas de relacionamento, com parceiros do mesmo sexo. Vivendo uma sexualidade não reprodutiva, mas compartilhando valores sociais e simbólicos de descendência e de família, que valorizam a reprodução, essas pessoas vislumbram nas técnicas médicas a chance de constituírem uma família com prole.

O encontro homossexual para gerar filhos dispondo das TR pode ocorrer pelo uso de material genético de terceiros com envolvimento de um ou ambos (apenas no caso das mulheres) os parceiros no processo. No Brasil, em termos normativos, não há restrição ao uso das técnicas para lésbicas ou gays. No entanto, entre homossexuais masculinos, estudos indicam que a adoção tem sido mais utilizada, já que há maiores dificuldades em usar a gestação substituta (ZAMBRANO, 2006; UZIEL, 2007;). Só recentemente, o Conselho Federal de Medicina explicitou na norma médica a possibilidade destes recorrerem a técnicas de reprodução assistida (CFM, 2013).

Pode-se afirmar que a família permanece na sociedade contemporânea ocidental como uma instituição fundamental de sociabilidade, núcleo central a partir do qual se estruturam e transmitem importantes valores da cultura. Nesse sentido, apesar de inúmeras modificações em seu domínio, resultantes de processos como a maior presença da mulher no mercado de trabalho, o advento do divórcio, o controle da fecundidade, a separação de sexualidade e reprodução e a visibilidade da homossexualidade, essa instituição ainda é reconhecida como a mais "natural" de todas.

A vinculação do fato biológico com o fato social ("naturalização") desse modelo histórico de família (a nuclear) reforçou a ideia de que uma criança só pode ter um pai e uma mãe, definidos (nem sempre de forma concomitante) como aqueles que são a origem do material genético, do vínculo com um grupamento (parentesco), do reconhecimento jurídico (filiação) e do exercício da função parental (cuidado com alimentação, educação, saúde). Entretanto, o surgimento das TR abala esse quadro, por possibilitar que uma criança nasça sem ter qualquer relação biológica ou genética com aqueles que a gestam e permitir a um potencial progenitor ter acesso à fecundidade de terceiros. A criança pode ser fruto de 
sêmen e óvulos doados e ter sido gestada por uma terceira pessoa ou possuir material genético de apenas um dos pais. Nesses termos, as TR introduziram uma nova distinção, com o parente biológico como uma categoria separada do parente social (STRATHERN, 1991; BARBOSA, 1999; CORRÊA, 2001).

A partir do surgimento das TR, a compreensão da maternidade como uma situação evidente, já que fundada na biologia, pode ser dividida em três: a "mãe" que doa os óvulos para serem fecundados, a "mãe" que gesta a criança no útero e a "mãe social", que irá criar a criança. Nesse sentido, a norma amplamente adotada, que define a mãe como aquela que dá a luz, é discutível no âmbito das tecnologias reprodutivas. Já a paternidade, atribuída em várias legislaçôes pela inferência de relacionamento de um homem com a mulher que se torna mãe, torna-se mais fluída, e a confirmação de paternidade biológica pode demandar comprovação por meio de testagem genética (FONSECA, 2011; ALMEIDA, 2009).

A construção de um projeto de filiação por lésbicas, temática recortada neste artigo, não é um fato recente e relacionado somente à tecnologia. No passado, lésbicas e gays frequentemente tornavam-se pais e mães em razão de relacionamento heterossexual prévio, adoção ou mesmo autoinseminação (HAYDEN, 1995; JONES, 2005; HAIMES; WEINER, 2000; DUNNE, 2000; FONSECA, 2008). A possibilidade de acessar tecnologias reprodutivas para viabilizar esse projeto causou inicialmente muita resistência no meio médico (PERELSON, 2006). No entanto, atualmente, a prática é prevista em vários países em contextos relativamente diversificados (RYAN-FLOOD, 2009; LUCE, 2010; THOMPSON, 2005; MAMO, 2007; 2010; JONES, 2005; HAYDEN, 1995).

Casais heterossexuais têm sido os "legítimos" usuários das tecnologias reprodutivas por serem reconhecidos pela Medicina como os usuários de fato dos tratamentos destinados a restaurar ou promover a característica tida como inerente à união heterossexual - a procriação (MAMO, 2007; MACHIN, 2014). As situações de casais homossexuais ou mesmo de mulheres solteiras são percebidas como envoltas em questóes éticas, como já demonstrou a literatura sociológica e antropológica que trata das TR (FRANKLIN, 2001; THOMPSON, 2005; MAMO, 2007; LUCE, 2010).

Nesse sentido, a demanda formulada por lésbicas para concepção desafia preceitos socialmente estabelecidos sobre a importância e a posição da figura paterna na família e as regras relativas ao intercurso sexual na reprodução. A ideia 
das TR serem um "instrumento" que possibilita a gestação nesses casos provoca desconforto em profissionais médicos, como bem observou Strathern (1995) ao abordar a conhecida Síndrome do Nascimento Virgem.

A definição médica formulada sobre infertilidade, como uma disfunção ou falta de habilidade para reproduzir a partir de determinado período de tempo de ocorrência de relações sexuais desprotegidas (CORRÊA, 2001; MACHIN, 2000), não encontra correspondência entre lésbicas. Quando não há gravidez, esta não pode ser identificada com uma inabilidade física, mas como um tipo particular de situação social, que demanda tratamento e é codificada em termos médicos como ausência de sêmen (MAMO, 2007).

Partindo do contexto de construção de um projeto de filiação por gays e lésbicas, o estudo desenvolvido colocou em perspectiva as escolhas dos sujeitos quanto às alternativas consideradas na elaboração do projeto de parentalidade, estabelecendo um contraste entre os dois campos compreendidos na configuração da família: a adoção e as tecnologias reprodutivas. As narrativas produzidas possibilitaram explorar os processos envolvidos nas adoções e no uso de TR, já que foram entrevistados casais que planejavam ter filhos (e analisavam os meios para sua efetivação) e aqueles que estavam em processo de adoção ou de utilização de TR. No presente artigo, nosso foco de análise se volta às experiências de lésbicas em tratamentos de reprodução assistida e ao uso que fazem de bancos de sêmen nesse processo. Abordaremos questôes relativas à obtenção desse material genético e discutiremos a hereditariedade e a genética enquanto categorias norteadoras de escolhas e decisões no contexto do uso das TR por esses casais, considerando ainda o papel dos profissionais na mediação das escolhas e do acesso ao material genético.

\section{Metodologia}

A análise apresentada faz parte de um estudo qualitativo ${ }^{2}$ mais amplo que aborda as temáticas da adoção e das tecnologias reprodutivas na construção de novas configurações familiares. Seus dados foram coletados em fontes variadas de 2010 a 2012 na região da Grande São Paulo, Brasil. No recorte aqui proposto, utilizaremos os dados empíricos advindos de entrevistas em profundidade com profissionais de saúde e casais de lésbicas em processos de reprodução assistida.

O uso dessa técnica possibilitou o resgate da dimensão simbólica e da subjetividade expressa nas falas das mulheres e dos profissionais de saúde 
entrevistados. Em outros termos, a partir da entrevista em profundidade, foi possível captar sistemas de valores, crenças e normas que orientam e sustentam as escolhas das mulheres, bem como a atuação dos profissionais que lidam com a demanda de lésbicas no âmbito da clínica em reprodução assistida. As entrevistas, portanto, permitiram apreender a forma como esses sujeitos dão sentido às experiências vividas nesse contexto, na medida em que a fala de alguns pode, tal como sustentam Bourdieu, Chamboredon e Passeron (2004), ser representativa e informar maneiras de compreender, significar, perceber e agir de grupos sociais em determinados contextos históricos, sociais e culturais.

Também foi realizado levantamento junto a sites no Brasil e nos Estados Unidos da América no tocante aos contextos legais e técnico-científicos relacionados às práticas do campo das TR quanto aos critérios relacionados ao uso de bancos de sêmen, screening, recrutamento e seleção de provedores ${ }^{3}$.

Ao todo, foram entrevistados dez profissionais de saúde (três psicólogas, cinco médicos especialistas em TR, um embriologista e um urologista) e vinte mulheres (dez casais) que estavam em processo de tratamento à época das entrevistas. Quanto às mulheres, foram usados dois modos de acesso: o primeiro consistiu na indicação por profissionais entrevistados de clientes que estavam em processo de tratamento e o segundo, contato com redes sociais e comunidades lésbicas 4 .

As entrevistas seguiram um roteiro que abordou temáticas como a trajetória afetivo-sexual; concepções de gênero, família e reprodução; autonomia, independência e laços de família e parentesco; projeto de filiação, expectativas e vivência no uso de tecnologias reprodutivas. Levaram-se em conta os preceitos éticos da pesquisa ${ }^{5}$, dentre os quais se destacam o caráter voluntário da participação, o anonimato ${ }^{6}$ e a confidencialidade das informações. As entrevistas ocorreram em locais escolhidos pelos próprios participantes, no caso das mulheres - no geral, em suas próprias residências - e, entre os profissionais de saúde, nos seus locais de trabalho. As entrevistas com os casais foram mais longas ${ }^{7}$, com duração aproximada de duas horas; já as realizadas com os profissionais duraram aproximadamente trinta minutos. Todas foram gravadas e transcritas.

Os dados foram analisados considerando os seguintes procedimentos: leitura exaustiva de cada entrevista, estabelecimento de categorias temáticas, organização e análise do material segundo essas categorias e cotejamento dos conteúdos das categorias com a literatura existente sobre a temática geral e com as referências teóricas que nortearam a pesquisa. 
Os profissionais entrevistados apresentam um perfil de formação heterogêneo, mas com atuação na área de TR há mais de 10 anos. Em sua maioria, estavam inseridos em clínicas privadas e também no setor público, especificamente em instituições de ensino superior. As mulheres entrevistadas têm entre 28 e 51 anos de idade, são brancas, com alto nível de escolaridade e representativas de camadas médias urbanas. Destacamos que o perfil relativamente homogêneo das entrevistadas não caracteriza uma situação buscada, mas resulta do perfil da clientela atendida em serviços de alto custo em reprodução assistida no país.

\section{Reprodução entre lésbicas: negociando a concepção}

Um projeto de filiação se revela uma construção que considera uma variedade de desejos, possibilidades legais e condições para se efetivar ${ }^{8}$. As narrativas indicam que, quando se faz uma demanda para a Medicina Reprodutiva, vários outros caminhos são pensados, buscados e avaliados. Nesse contexto, as TR são valorizadas por permitirem a vivência dos processos ligados à reprodução (gestação, parto e amamentação) em detrimento da adoção. Esta só figurou como possibilidade entre as mulheres, em geral, quando o alto custo dos procedimentos os impossibilitava.

Quando chegaram às clínicas, em regra, as mulheres já tinham certa clareza do que gostariam de fazer e de quem iria gestar. Quanto a este aspecto, a decisão baseou-se em acordos que envolveram diferentes perspectivas. Questões como identidade de gênero, idade e profissão foram elementos apresentados pelas mulheres como determinantes nesse processo. Como a multiplicidade de aspectos envolvidos nessa escolha por parte das lésbicas não era reconhecida e, portanto, explorada pelos médicos, para estes, a definição sobre quem gesta no casal guarda correspondência com sua visão de modelos e papéis tradicionais de gênero masculino/feminino existentes entre as lésbicas. Entretanto, essa noção não encontrou correspondência nos relatos colhidos entre as mulheres.

De fato, casais de lésbicas representam um perfil diferente dos casais heterossexuais inférteis que se submetem a tratamentos, na medida em que, muitas vezes, esses últimos tendem a ser percebidos como mais vulneráveis em razão de uma alegada incapacidade para reproduzir (BARBOSA, 1999). No caso das lésbicas, essa possibilidade decorrente de uma condição de saúde não se 
configura. Nas narrativas médicas, elas são definidas como detentoras de mais maturidade e objetividade nos processos envolvidos nos tratamentos.

Os projetos também revelaram a busca pela valorização da autonomia do casal por privilegiarem o não envolvimento parental de uma terceira parte no processo. Optaram pelo acesso à tecnologia reprodutiva e pelo uso de um provedor desconhecido de sêmen. Havia um receio de que um conhecido (amigo ou parente, por exemplo) desejasse exercer o papel de pai ou estar próximo à criança. Essa posição parece se ancorar em dois aspectos: um receio de que essa terceira parte queira participar de fato do desenvolvimento da criança e os riscos legais que o casal de mulheres pode correr acaso esse homem futuramente entre na justiça pelo reconhecimento legal de sua paternidade, retirando o lugar da comãe.

Nos encontros iniciais onde ocorreram as negociações com os profissionais de saúde sobre quais as melhores opções a serem consideradas, a técnica ROPA (Recepção de Óvulo da Parceira) representou uma demanda frequente das lésbicas. Na prática, essa técnica corresponde a um processo de ovo doação com inseminação de sêmen de doador (ID). Uma das mulheres fornece o óvulo e a parceira gesta. Segundo Grossi (2003), esse é o maior desejo entre lésbicas no país, o que corrobora os nossos achados. O uso da técnica é descrito em outros países como Espanha (MARINA et al., 2010) e Estados Unidos (MAMO, 2007; THOMPSON, 2005), mas não parece ter a mesma dimensão e demanda como no Brasil (CORREA, 2012; MACHIN, 2014).

Interessa registrar que essa situação tem sido ofertada e estimulada pelos profissionais médicos mesmo quando as mulheres desconhecem essa possibilidade. Em alguns depoimentos, lésbicas mencionaram que achavam essa ideia uma utopia e não imaginavam ser possível, mas que ela teria sido sugerida pelo médico para que "fizessem o que todas estão fazendo". Nesse procedimento, há uma vinculação biológica e legal das duas mulheres no processo com uso de sêmen proveniente de um banco. A técnica permite a um só tempo o vínculo legal e biológico/genético entre as envolvidas no projeto de filiação, o que pode explicar o interesse despertado com a prática. Destaca-se ainda o fato da técnica reatualizar o ideal de amor romântico. No país, já há jurisprudência com a emissão de certidão de nascimento da criança com o nome das duas mães.

Importa considerar que, sob uma perspectiva médica, ambas as parceiras devem se submeter aos procedimentos e medicamentos, que são mais complexos 
1262 e caros que um procedimento de inseminação artificial com uso de provedor de sêmen para uma única mulher.

$\mathrm{Na}$ impossibilidade do processo da ROPA ocorrer em razão da idade avançada de uma das parceiras (e, com isso, o uso de seu óvulo ser descartado ou sua gestação ser considerada inadequada), o uso do banco de sêmen adquiriu maior peso simbólico entre as entrevistadas. Dessa maneira, buscar-se-ia a adequação fenotípica do provedor de sêmen com o perfil daquela que não iria gestar ou fornecer seus óvulos para o processo, num indicativo da busca por eternizar os vínculos construídos. Há uma procura de estratégias para "deslocar" a substância biogenética do provedor e produzir uma criança com conexão com ambas (HAYDEN, 1995). Nesse sentido, a ênfase não está somente no parentesco, mas em diferentes práticas construídas em torno de uma cultura de conectividade, conforme descrito por Carsten (2000).

\section{O consumo procriativo no mercado de sêmen internacional e as possibilidades das lésbicas brasileiras}

$\mathrm{Na}$ década de 2000, Daniels e Golden (2004) descreveram o cenário de um visitante num dos maiores bancos de sêmen dos Estados Unidos, o New England Cryogenics, onde é possível se encontrar um amplo estoque seminal para compra. São mais de 165.000 amostras de sêmen "representando o melhor que os homens americanos têm para oferecer". É possível ter acesso a parte do material ${ }^{9}$ a partir de listas e catálogos para venda acessíveis no site da empresa.

Para conhecer um pouco mais desse mercado, é importante considerar que os provedores de sêmen e seu material são objeto de testagem para assegurar sua saúde e sua identificação com um determinado padrão de mercado. Muitos fornecedores são rejeitados se considerados muito jovens (menos de 21 anos) ou muito velhos (mais de 35 anos); se são muito baixos (menos de $1.76 \mathrm{~cm}$ ) ou muito altos (mais de $1.88 \mathrm{~cm}$ ); se são muito gordos ou magros; se são adotados ou tem pais adotivos (em razão de não poderem fornecer dados completos sobre genética). Outras razões que impedem a venda do material genético são homens que fazem ou fizeram sexo com homens ou com mulheres, que tenham tido sexo com homens bissexuais ou com muitos parceiros. Passando nessa primeira seleção, o provedor passará por testes de sangue, urina, checagem para uso de 
drogas, HIV e uma série de outras doenças infecciosas ${ }^{10}$. Passados os testes, os provedores são numerados e categorizados por raça e origem étnica.

O crescimento dessa indústria nos Estados Unidos nas últimas duas décadas revela o lugar atribuído ao desejo de obter material genético visando uma filiação com determinadas características e a prevalência de hierarquias sociais específicas conforme apontado por Daniels (2006), Daniels e Golden (2004), Daniels e Haimes (1998) e Schmidt e Moore (1998).

Em termos históricos, o desenvolvimento do uso de inseminação artificial esteve vinculado à infertilidade feminina quando o sêmen do marido era inserido na cavidade uterina, na denominada inseminação artificial homóloga (DANIELS; GOLDEN, 2004). Sob o ponto de vista da igreja, o processo quebrava o casamento pela via do ato da masturbação. Um centro de doação de esperma vinculado à Georgetown University School of Medicine foi criado em 1938 com material oriundo de estudantes de Medicina.

Nesse período, dissemina-se a discussão quanto à correspondência do provedor com as características do homem do casal, havendo preocupação com a escolha reprodutiva em oferecer um potencial para produzir bebês melhores, a partir de um processo de escolha cuidadosa do provedor que o banco de sêmen pode proporcionar (DANIELS; GOLDEN, 2004). O geneticista Sheldon Reed, em 1947, caracteriza seu trabalho com o termo "aconselhamento genético" contribuindo com a ideia de controle das crianças produzidas por meio de ID.

A possibilidade do congelamento do sêmen cria efetivamente as condiçõos para a expansão dos bancos de sêmen. Em 1953, relata-se o nascimento dos primeiros bebês a partir de sêmen congelado (DANIELS; GOLDEN, 2004). Mas é somente com o surgimento da Aids que as amostras utilizadas passam todas a ser congeladas.

Em 2013, havia 150 bancos de sêmen nos Estados Unidos segundo relato colhido para esta pesquisa. Alguns trabalham somente com médicos, outros vendem as amostras para pessoas físicas para inseminação doméstica (caseira). Dentre estes, há um banco que atua de forma não lucrativa (The Sperm Bank of California) e é vinculado a Oakland Feminist Women's Health Center; outros três atuam direcionados a atender famílias não tradicionais e lésbicas, e há outro especializado em sêmen de "gênios" - Hereditary Choice in California (DANIELS; GOLDEN, 2004). 
Os princípios que governam essa prática são identificáveis em outros ramos de mercado e varejo, quanto ao acesso ao produto, envio de amostra por correio, compra com cartão de crédito e marketing via internet. Os bancos de sêmen trabalham com a demanda do consumidor e valorizam seu "potencial" para agregar valor ao material que comercializam, criando todo um imaginário que articula as possiblidades da ciência em selecionar os provedores mais adequados para proporcionar o "melhor bebê" (DANIELS, 2006).

Trazendo a discussão para o contexto brasileiro, existem no país somente dois bancos de sêmen, localizados na cidade de São Paulo, responsáveis pelo fornecimento de amostras a diversas clínicas e mesmo a outros países na América Latina. Como, pela legislação brasileira, o sêmen não pode ser comercializado e os provedores não podem receber dinheiro pelo material (nem mesmo ajuda de custo), bancos e clínicas de reprodução assistida mencionam haver muita dificuldade na obtenção de provedores ${ }^{11}$.

Os depoimentos colhidos entre as lésbicas problematizam a pouca disponibilidade de provedores nos bancos de sêmen brasileiros e as informações sobre o seu perfil, como, por exemplo, dados sobre histórico familiar de doenças. Cíntia e Sílvia fizeram cinco procedimentos utilizando sêmen de provedores no Brasil buscando adequar as características fenotípicas do provedor às de Cintia, que não participaria geneticamente do processo. Após essas tentativas, importaram sêmen dos Estados Unidos.

\begin{abstract}
Eu não encontrava nenhum ruivo... encontrar um branquinho lá já é difícil... e eu falei, eu não acredito que estou gastando tanto dinheiro... um era taxista, o outro terapeuta... não é questão de preconceito, não tenho nada contra taxista... até talvez ele tivesse uma carga genética maravilhosa, uma pessoa linda e tudo mais. Mas, você começa a pensar que tudo tem a ver... mas eu não sei se o cara é esquizofrênico, se toda a família morreu de câncer de fígado, sabe esse tipo de coisas? Que em um banco americano você tem, você tem essa informação... eu não me sentia segura. Não, eu escolhia assim, tipo o menos pior e aquilo estava me dando um negocio ruim sabe?
\end{abstract}

A solicitação de sêmen para os procedimentos é feita pelas clínicas aos bancos brasileiros, que fornecem uma lista das amostras disponíveis e compatíveis com o pedido do casal, considerando compatibilidade imunológica e semelhanças fenotípicas $^{12}$. Dessa lista, constam dados como tipo sanguíneo, altura, peso, constituição óssea, raça, origem étnica, cor dos olhos, cor do cabelo e textura, cor de pele, ascendência dos pais, profissão, escolaridade, hobby e religião. 
Segundo Costa (2007), enquanto alguns dados relativos aos provedores de sêmen são observados e registrados pelo corpo médico do banco, outros são perguntados aos provedores. Como definições relativas à raça, cor de pele e etnicidade guardam relação com a posição social dos indivíduos (distinção de classe, gênero), sendo a cor um elemento negociado em certos contextos sociais, esse procedimento resultaria em imprecisões a respeito de algumas características.

Para os depoentes vinculados a bancos de sêmen brasileiros, as informações apresentadas aos pacientes seriam similares àquelas disponibilizadas por bancos de sêmen de outros países como os Estados Unidos. Dados relativos ao screening realizado ou mesmo sobre o histórico de doenças familiares são levantados, mas não parecem ser disponibilizados aos pacientes. Importa considerar nesse contexto quais informações sobre características fenotípicas são relacionadas à hereditariedade e como isso é manejado por casais demandantes e por profissionais envolvidos na classificação dos provedores, na medida em que, atualmente, a genética tem tido profunda influência nos discursos relativos à compreensão sobre saúde e doença, que se tornaram bastante genetizadas (LUNA, 2007; MAMO, 2007).

Carla e Júlia falam desse processo de escolha do sêmen, num contexto familiar que envolveu inclusive suas filhas, e quais os critérios buscados.

\footnotetext{
Nós ficamos com uma lista de 80 nomes, e, imagina... somos quatro mulheres para chegar num consenso... na verdade eu acho que tem informaçôes que eles colocam que são desnecessárias, e o que realmente importa fica de fora. Não tem um quadro de doenças da família, por exemplo... quando a gente ia fazer a inseminação a gente pensou alguém mais parecido comigo, já que ia ser com o óvulo dela... e quando a gente foi para a FIV para a troca de óvulos, a gente procurou mais parecido com ela, e as crianças, na verdade cada um de nós escolheu sete (7). A reivindicação das crianças era que não queriam ninguém com olho azul porque não tem ninguém assim aqui... então nós procuramos mais parecido com a Júlia, com ossos pequenos, o tipo físico. $\mathrm{E}$ as crianças optando pelo irmão parecer um pouco com elas também.
}

Há um desejo, portanto, por maximizar conexões estabelecendo um link da filiação com características fenotípicas presentes na família, no casal e em suas filhas, num arranjo que proporcione uma percepção de "natural" conexão.

Como bem documentado nos estudos em Ciências Sociais e gênero no âmbito de práticas em torno do uso de provedor de sêmen, casais heterossexuais buscam realizar correspondência entre o receptor e o provedor de forma a facilitar o reconhecimento de similaridade "genética" entre membros da família, mantendo a ideia de segredo em torno da prática, com a semelhança fenotípica atuando como 
substituta simbólica da transmissão de genes (DANIELS, 2006; SCHMIDT; MOORE, 1998; DANIELS; HAIMES, 1998; JONES, 2005; HAIMES; WEINER, 2000; COSTA, 2007). Entre lésbicas, a busca de correspondência com as integrantes do casal, facilitando a criação de link como o de uma família genética tem sido igualmente destacada pela literatura (JONES, 2005; THOMPSON, 2005; MAMO, 2007; HAYDEN, 1995). Elas objetivam gerenciar práticas que permitam estabelecer laços entre ambas e a criança a ser concebida, conferindo à biologia um lugar simbólico de representação do compartilhamento do vínculo criado. A construção não está baseada na ideia de manter o "segredo" em torno da prática, na medida em que sua reprodução por princípio é infecunda.

Lúcia e Gabriela realizaram um procedimento de FIV com inseminação com provedor de banco brasileiro e reportaram insegurança na escolha e dificuldade em encontrar um provedor com características correspondentes a Lúcia, que iria gestar com o óvulo de sua parceira Gabriela.

A Lúcia tem olho azul e cabelo claro, então com o óvulo dela, a gente sempre pro-
curava uma pessoa super recessiva, loira de olho azul, que é para ter a chance de
parecer com ela... aí, um é super baixo, o outro é raquítico, o outro é careca... aí,
você fica assim - o que eu faço? Então, no fim a gente não teve escolha, teve que
pegar aquele único, né.

A busca de sêmen adequado para o procedimento foi descrita como um processo em que há poucas escolhas a serem feitas, pois os dois bancos existentes no país não possuem amostras com as características físicas (quanto à cor de cabelo, olhos e pele) que as mulheres demandam. De acordo com um entrevistado ligado a banco de sêmen no país, os doadores têm características fenotípicas próximas à maioria da população brasileira.

Origem e identidade étnica, geográfica e ancestral evocam como sujeitos e famílias "sabem" sobre si e como se situam em relação a outros grupos, tendo um papel importante no reconhecimento de seu pertencimento (MAMO, 2007). A pouca disponibilidade de sêmen tem levado as clínicas a importar amostras dos EUA para lésbicas. Ademais, a ideia de não se encontrar sêmen que corresponda às características fenotípicas de demandantes dos serviços privados de TR no Brasil foi mencionada pelo diretor de um dos maiores bancos americanos como razão para o crescimento dessa demanda. A importação é permitida, desde que se comprove por meio de declaração dos bancos brasileiros que não se dispóe de amostra com as características solicitadas. 
Nesse contexto, também estão presentes ideias relativas à identidade étnica e ideologias discriminatórias de raça/cor, que representam hierarquias reveladoras de desigualdades sociais. Os provedores são percebidos como pessoas que não têm características fenotípicas semelhantes e podem dispor de pouco capital cultural ou de uma origem social distinta, numa análise promotora da "naturalização" de traços sociais.

As observações sobre características sociais envolvidas na reprodução remetem a uma antiga configuração físico-moral (degeneração) ou mesmo aos referenciais da Sociobiologia (LUNA, 2007). As narrativas articulam a filiação por meio do parentesco genético; mas lembremos que a genética fala de características singulares constituintes dos indivíduos e igualmente dos laços de sangue (STRATHERN, 1995). Abreu Filho (1982, p. 98) considera que, para as categorias de parentesco no Brasil, o sangue é entendido como articulador da ordem da natureza com a ordem da cultura, sendo substância envolvida com a transmissão de "qualidades físicas e morais, formando o corpo e o caráter" e tornando-se assim um vetor de representações físicas e também morais.

A procura por sêmen nos bancos americanos foi descrita como algo "super divertido", que possibilitava ter mais segurança na escolha, pois permitia "ver mais" do provedor, ser menos impessoal, conforme alegado num dos depoimentos, em oposição ao contexto dos bancos no Brasil. Dois elementos são destacados nos depoimentos: acesso ao histórico de saúde familiar do provedor e clareza quanto às suas características fenotípicas, na medida em que é possível ter acesso à sua imagem. Importa nesse contexto considerar que saber mais sobre o provedor não envolve ter um acesso futuro à sua identidade, quando a criança concebida completar a maioridade. Essa possibilidade disponível para alguns provedores de sêmen no exterior não é vista como algo desejável pelas entrevistadas, pois valorizam o princípio do anonimato previsto no país quanto à doação de material genético.

Nos EUA, são estudantes universitários, super saudáveis, que mal entraram na vida de bebida, ainda estão super sarados, super atléticos... a gente comprou foto do cara de criança, a gente ouvia a voz... Então você cria um laço, que você não cria no banco de sêmen brasileiro. E o que a gente quis é a cara da Lúcia quando era pequena.. impressionante, são assustadoramente iguais, de confundir quase... e você tem a árvore, o pai, a mãe dele, irlandês e germânico, italiano e português... tem histórico de doença da família inteira. Eu falei... minha avó teve câncer de mama, eu tive dois tios que morreram de câncer, eu não quero um cara com câncer. 
Assim, se há dúvidas sobre quem é o provedor no Brasil (que precisa ter sua identidade protegida pelo anonimato) e a relação é mediada pela clínica de reprodução e o banco de sêmen, a busca no exterior é liberada pelas clínicas, e as próprias usuárias podem, por meio da web, definir o perfil adequado do provedor. Num prazo de 20 dias, as amostras solicitadas já se encontram disponíveis para o procedimento.

A proliferação da crença da genética na determinação de um crescente conjunto de características e doenças é um elemento-chave para os bancos de sêmen, que constroem discursos de reprodução como um risco, para o qual sua atividade garantiria a segurança do "produto" a ser vendido (MAMO, 2007; DANIELS, 2006). Assim, essa integridade na reprodução é marcada pelo uso de procedimentos que garantem a testagem do sêmen e a seletividade dos homens que participam dos bancos. De acordo com Daniels (2006), a indústria de sêmen trabalha com um ideal de masculinidade ocidental, no qual a aprovação na seleção como "doador" (ele é remunerado) diz respeito não unicamente a um perfil de saúde, mas à sua proximidade a esse ideal: alto, magro, bonito, bem educado e atlético.

Esse imaginário de masculinidade é captado pelos consumidores, que "se encantam" com a possibilidade de escolha oferecida pelos catálogos na promoção do papel da "semente masculina" na qualidade da reprodução (DANIELS, 2006). A força dessa ideia estabelece um link entre parentesco e reprodução, como se as escolhas de correspondência entre usuárias e provedores pudessem se materializar na presente filiação (MAMO, 2007). Gabriela comenta:

Aí tem a questão da beleza, tem a questão da cultura, tem a questão da saúde, tem a questão da procedência... Você pelo menos consegue ter uma relação virtual com a pessoa, tipo conhecer um namorado na internet.

A maior demanda por informações sobre o histórico de doenças familiares do provedor invoca a noção contemporânea da importância dos genes na transmissão de patologias. Cintia e Silvia destacam sua confiança nesse aspecto:

Aparece a seleção de todos que têm as características que você escolheu. É fantástico. Eu pirei, no final ficaram cinco. Dessa vez, eu escolhi o melhor, o cara tem uma saúde perfeita, estou tranquila com a saúde do cara... todas as gerações...

Fica evidente um desejo de, por meio da busca do melhor histórico de saúde familiar do provedor, proporcionar uma descendência melhorada, redesenhar, por meio da oportunidade de escolha ofertada pela tecnociência, um futuro diferente 
aprimorando a biologia que se herda. Sinal do processo de genetização do parentesco (FRANKLIN, 1999), considerado como propriedade de indivíduos vistos como entidades separadas, desconectadas de suas relações, em oposição à noção vinculada ao sangue como elemento, que opera de forma simbólica "ligando" os indivíduos (LUNA, 2007).

Ademais, há um temor associado ao "sangue" que não se conhece, uma preocupação com a herança genética de doenças fomentando a medicalização do parentesco (FINKLER, 2000). Essa situação está em consonância com a valorização nas sociedades ocidentais do consumo de produtos médicos associada à importância da ideologia de escolha individual na construção de projetos (MAMO, 2007).

\section{Consideraçōes finais}

A partir da trajetória empreendida, destacamos alguns aspectos. As TR são valorizadas por possibilitarem a reprodução sem que se faça uso de uma "solução doméstica”, com provedor conhecido, pelo risco deste desejar ou forçar, em algum momento, o envolvimento com a filiação. As narrativas destacam igualmente um controle na escolha do sêmen, melhorando a qualidade da filiação, quanto a possíveis doenças associadas à nova geração.

Nas narrativas sobre o desejo de ter filhos, sobressai um projeto conjunto que vincula a história pessoal com o interesse pela maternidade e pela vivência da gestação, do parto e da amamentação e aquela relativa à família de origem. Ter um filho é visto como um importante passo no reconhecimento e afirmação da família construída, inclusive possibilitando uma (re)aproximação com suas famílias de origem, quando a descoberta da sexualidade teria provocado afastamentos. Contudo, a ideia de um filho biologicamente vinculado a ambas não é referida como uma condição para a aceitação em suas famílias de origem.

O projeto de filiação deve lidar com as repercussões legais e os aspectos afetivos vinculados às escolhas. Nesse contexto, a demanda por conexões biogenéticas envolvendo ambas as parceiras do casal (ROPA) mina a visão dominante da impossibilidade de reprodução em casais de mesmo sexo e possibilita a quebra de relaçôes assimétricas entre as integrantes do casal e a criança.

$\mathrm{O}$ reforço à construção de laços biológicos por lésbicas conjuga ideias tradicionais de parentesco com a dimensão da reprodução baseada em escolhas 
por meio da TR. O lugar da ROPA, a busca por determinados sêmens ou a sua importação exigem ponderações das mulheres e revelam trajetórias construídas voltadas a assegurar reconhecimento legal e social das relaçōes e famílias elegidas por meio das TR.

Como observa Almeida (2009), a dinâmica reprodutiva e parental atuante em arranjos lésbicos e gays guarda ainda os efeitos hegemônicos presentes na ordem de gênero e na ordem heteronormativa que lhe subjaz, mas também desafia, ao mesmo tempo, modelos de gênero e de relações parentais.

Somado a isso, devemos trazer ao debate no campo das TR a tensão oriunda da legislação brasileira, que determina o anonimato do doador, com o desejo expresso pelas lésbicas de saber mais das características do material genético que estão adquirindo. Finalmente, a discussão não pode se furtar a considerar as repercussões que essas escolhas (aparentemente individuais) produzem em termos de reforço de diferenças e desigualdades sociais, étnicas e de raça/cor no cenário analisado, bem como questionar a relevância atribuída aos laços biológicos por meio de uma estratégia de manipulação das origens genéticas, o que pode indicar a supremacia da "natureza" frente aos arranjos socialmente estabelecidos. ${ }^{13}$

\section{Referências}

ABREU FILHO, O. de. Parentesco e identidade social. Anuário Antropológico/80. Rio de Janeiro: Tempo Brasileiro, 1982.

ALMEIDA, M.V. O esperma sagrado. Algumas ambiguidades da homoparentalidade em contextos euro-americanos contemporâneos. Quaderns, v. 25, p. 109-121, 2009.

BARBOSA, R. M. Desejo de filhos e infertilidade: um estudo sobre a reprodução assistida no Brasil. Tese (Doutorado em Sociologia) - Faculdade de Filosofia, Letras e Ciências Humanas. Universidade de São Paulo, São Paulo, 1999.

BOURDiEU, P.; CHAMBOREDON, J-C; PASSERON, J-C. Oficio de Sociólogo. Metodologia da pesquisa na sociologia. Petrópolis: Vozes, 2004. 337p.

CARSTEN, J. (Ed.). Cultures of relatedness: new approaches to the study of Kinship. Cambridge: Cambridge University Press, 2000. 228p.

CONSELHO FEDERAL DE MEDICINA. Resolução 2013/2013. Brasília/DF. Disponível em: http://www.portalmedico.org.br/resolucoes/CFM/2013/2013_2013.pdf). Acesso em: 07 jul. 2013.

CORRÊA, M.V. Novas tecnologias reprodutivas. Limites da biologia ou biologia sem limites? Rio de Janeiro: EdUERJ, 2001. 
CORRÊA, M.E.C. Duas mães? Mulheres lésbicas e maternidade. Tese (Doutorado em

Saúde Pública) - Faculdade de Saúde Pública. Universidade de São Paulo, São Paulo, 2012.

COSTA, R.G. Racial classification regarding semen donor selection in Brazil. Developing World Bioethics. V. 7, n. 2.p.104-111, 2007.

DANIELS, C.R. Exposing men. The science and politics of male reproduction. Oxford: Oxford University Press, 2006. 276p.

DANIELS, C.R.; GOLDEN, J. Procreative compounds: popular eugenics, artificial insemination and the rise of the American sperm banking industry. Journal of Social History, v.38, n.1, p.5-27, 2004.

DANIELS, K.; HAIMES, E. (Ed.). Donor insemination: international social science perspectives. Cambridge: Cambridge University Press, 1998. 185p.

DUNNE, G. A. Opting into motherhood: lesbians blurring the boundaries and transforming the meaning of parenthood and kinship. Gender \& Society, v. 14, n. 1, p. 11-35, 2000.

FINKLER, K. Experiencing the new genetics. Family and kinship on the medical frontier. Philadelphia: University of Pennsylvania Press, 2000.

FONSECA, C. Law, technology and gender relations: following the path pf DNA paternity tests in Brazil. In: BROWNER, C.H.; SARGENT, C.F. (Eds). Reproduction, Globalization, and the State. New theoretical and ethnographic perspectives. Durham and London: Duke University Press, 2011. p. 138-153.

. Homoparentalidade: novas luzes sobre o parentesco. Estudos Feministas. V. 16, n. 3, p. 1-8, 2008.

FRANKLIN, S.; MCKINNON, S. (Ed.). Relative values: reconfiguring kinship studies. Durham, NC, and London: Duke University Press, 2001, 519p.

GROSSI, M.P. Gênero e parentesco: famílias gays e lésbicas no Brasil. Cadernos Pagu, v. 21, p. 261-280, 2003.

HAIMES, E.; WEINER, K. "Everybody's got a dad...". Issues for lesbian families in the management of donor insemination”. Sociology of Health \& Ilness, v. 22, n. 4, p. 477-499, 2000 .

HAYDEN, C. Gender, genetics and generation: reformulating biology in lesbian kinship. Cultural Anthropologie, v. 10, n. 1, p. 41-63, 1995.

JONES, C. Looking like a family: negotiating bio-genetic continuity in British lesbian families using licensed donor insemination. Sexualities, v.8, n. 2, p. 221-237, 2005.

LUCE, J. Beyond expectation: lesbian/Bi/queer women and assisted conception. Toronto: University of Toronto Press, 2010. 304p.

LUNA, N. Provetas e clones: uma antropologia das novas tecnologias reprodutivas. Rio de Janeiro: Fiocruz, 2007. 299p. 
1272 MACHIN, R. Relações de gênero, infertilidade e novas tecnologias reprodutivas. Estudos Feministas,. v.8, n. 1, p. 212-228, 2000.

Sharing motherhood in lesbian reproductive practices. BioSocieties, v. 9, n. 1, p. 42-59, 2014.

MAMO, L. Queering reproduction: achieving pregnancy in the age of technoscience. Durham \& London: Duke University Press, 2007. 320p.

Fertility, INC.: Consumption and subjectification in U.S. lesbian reproductive practices. In: CLARKE, A.E. et al. (Eds.). Biomedicalization. Technoscience, health and illness in the U.S. Durham \& London: Duke University Press, 2010, p. 173-196.

MARINA, S. et al. Sharing motherhood: biological lesbian co-mothers, a new IVF indication. Human Reproduction, v. 25, n. 4, p. 938-941, 2010.

PERELSON, S. A parentalidade homossexual: uma exposição do debate psicanalítico no cenário francês atual. Estudos Feministas. v. 14, n. 3, 709-730, 2006.

RYAN-FLOOD, R. Lesbian motherhood. Gender, families and sexual citizenship. London: Palgrave Macmillan, 2009. 256p.

SCHMIDT, M. and MOORE, L.J. "Constructing a "good catch", picking a winner" In: DAVIS-FLOYD, R.; DUMIT, J (Eds). Cyborg babies: from techno-sex to techno-tots. New York and London: Routledge, 1998, p. 21-39.

STRATHERN, M. Parentesco por iniciativa: a possibilidade de escolha dos consumidores e as novas tecnologias da reprodução. In Análise social. Lisboa, Instituto de Ciências Sociais da Universidade de Lisboa, no.114, vol.XXVI, 1991, p. 1011-1022.

, M. Necessidade de país, necessidade de mães. Estudos Feministas. v. 2, n. 95, p. 303-329, 1995.

THOMPSON, C. "Strategic naturalizing: kinship, race and ethnicity", In: Making parents: the ontological choreography of reproductive technologies. Cambridge, Massachusetts: The MIT Press, 2005. p. 145-178.

UZIEL, A.P. Homossexualidade e adoção. Rio de Janeiro: Garamond, 2007. 219p.

ZAMBRANO, E. Parentalidades "impensáveis": pais/mães homossexuais, travestis e transexuais. Horizontes Antropológicos. v.12, n. 26,p. 123-147, 2006.

\section{Notas}

${ }^{1}$ Tecnologias reprodutivas designam tecnologias médicas incluindo, por exemplo, estimulação da ovulação, fertilização in vitro (FIV), inseminação com doador (ID), injeção intracitoplasmática de sêmen (ICSI) e são usadas para obter a gestação em contextos nos quais ela não pode ser obtida por relações sexuais. Similarmente, o termo reprodução assistida (RA) é usado.

${ }^{2}$ Este estudo contou com o apoio do Conselho Nacional de Desenvolvimento Científico e Tecnológico/CNPq durante Estágio de Pós-doutorado realizado pela primeira autora na London School of 
Economics and Political Science e na University of Cambridge em 2011/2012. Houve também um auxílio à pesquisa pela mesma instituição de fomento processo no 483081/2010-8. Não há conflito de interesses envolvido na pesquisa.

${ }^{3} \mathrm{O}$ homem que contribui com seu sêmen tem sido tradicionalmente chamado de doador. Contudo, o termo guarda imprecisões, em particular, quando há pagamento monetário envolvido. Optou-se por utilizar a expressão "provedor" (DANIELS; HAIMES, 1998).

${ }^{4} \mathrm{O}$ conjunto de entrevistas tem caráter mais ilustrativo do que representativo da população que usa as TR no país. Por tratar-se de prática ainda recente, os casos de mulheres ainda são poucos, e o trabalho de campo foi marcado pela dificuldade em localizar entrevistadas ou mesmo ter seu aceite em participar da pesquisa. Importa mencionar que as entrevistas foram realizadas antes da Resolução de 2013 do Conselho Federal de Medicina.

${ }^{5}$ A pesquisa foi aprovada pelo Comitê de Ética em Pesquisa da UNIFESP sob o número 1937/10.

${ }^{6}$ Nesse sentido, os nomes dos integrantes da pesquisa aqui apresentados são fictícios.

${ }^{7}$ A pedido das parceiras, as entrevistas com os casais foram realizadas conjuntamente.

${ }^{8}$ Destaca-se o papel das redes sociais e dos grupos de discussão, que compartilham informações, perspectivas legais e profissionais acessíveis para essas práticas.

${ }^{9}$ Cerca de metade das amostras armazenadas estão depositadas em segurança por homens em processo de quimioterapia, trabalhando em processos industriais perigosos, indo para a guerra ou mesmo viajando durante processo de ovulação de suas parceiras (DANIELS; GOLDEN, 2004, p. 21).

${ }^{10}$ De acordo com Schmidt e Moore (1998), conseguir ser aceito como "doador" seria equivalente a conseguir ser admitido em Harvard.

${ }^{11}$ Os provedores precisam comparecer cerca de cinco vezes ao banco antes da primeira doação. Inicialmente, fazem uma consulta médica, sorologias, espermograma, screening para várias doenças e, caso aprovados, devem colher cinco amostras de sêmen e retornar em seis meses para refazer as sorologias. A avaliação do material a ser doado está em conformidade com as recomendações da American Fertility Society and Human Fertilization Embriology Authority - HFEA/UK. De acordo com integrantes dos bancos, o perfil do provedor costuma ser um homem identificado como um provedor nato, que costuma doar (sangue, por exemplo) para ajudar as pessoas. Os provedores no Brasil nada recebem; contudo, o sêmen, após processado, é vendido pelos bancos às clínicas. Uma amostra de sêmen importado pode custar em torno de US $\$ 560,00$, enquanto o valor de uma amostra nacional estaria por volta de US\$790,00. Esses valores correspondem ao custo para testagem e preparação do material para os procedimentos.

${ }^{12}$ A própria Resolução Médica expressa a necessidade de semelhança entre doadores e receptores de gametas (CFM, 2013).

${ }^{13}$ R. Machin participou da concepção do artigo, análise e interpretação dos dados, redação da primeira versão do manuscrito, revisão crítica e aprovação da versão final. M.T. Couto participou da concepção do artigo, revisão crítica do conteúdo intelectual e aprovação final do manuscrito. 


\section{"Making the right choice": reproductive technologies, lesbian practices and use of semen banks}

Obtaining semen for reproduction is a key issue in the project design of lesbian motherhood. The process of choosing the genetic material involves considerations of cultural ideals, kinship and normative principles regarding fertility services. The manuscript is based on study of lesbians seeking parenthood through the use of reproductive technologies (RT) and acquisition of semen in banks in Brazil and abroad. The qualitative study made use of semi-structured interviews with health professionals working in RT (10) and lesbians (10 couples) undergoing treatment with RT in São Paulo/SP, Brazil, in 2010/2012. There is a desire to maximize connections by establishing a link with the phenotypic characteristics of membership in the family and the couple, in an arrangement that provides a perception of "natural" connection with the use of biology as an important symbol of sharing the bond created. Due to an alleged lack of available semen samples compatible with the demands made by lesbian couples there has been an increase in the importation of semen from the United States for the procedures leading to a number of new issues in terms of parenthood, choice and design of a family.

Key words: reproductive technology; lesbian motherhood; semen banks. 
No artigo "Fazendo a escolha certa": tecnologias reprodutivas, práticas lésbicas e uso de bancos de sêmen”, publicado em Physis: Revista de Saúde Coletiva, v. 24, n. 4, p. 1255-1274, 2014, DOI: http://dx.doi.org/10.1590/S010373312014000400012, na página 1255, as notas contendo filiação institucional das autoras estão erradas.

Onde se lê:

Rosana Machin ${ }^{1}$

Marcia Thereza Couto

${ }^{1}$ Departamento de Política, Planejamento e Administração em Saúde, Instituto de Medicina Social da UERJ (IMSUERJ). Rio de Janeiro-RJ, Brasil. Endereço eletrônico: gkronis@gmail.com

${ }^{2}$ Faculdade de Farmácia e Bioquímica, Universidade Federal de Juiz de Fora. Juiz de Fora-MG, Brasil. Endereço eletrônico: maria.helena@ufjf.edu.br

Leia-se:

Rosana Machin'

\section{Marcia Thereza Couto ${ }^{2}$}

\footnotetext{
${ }^{1}$ Universidade Federal de São Paulo. São Paulo-SP, Brasil. Endereço eletrônico: rosana.machin@gmail.com.

${ }^{2}$ Departamento de Medicina, Universidade de São Paulo. São Paulo-SP, Brasil. Endereço eletrônico: marthet@usp.br.
} 